\title{
The diagnostic importance of evaluation of solid breast masses by sonoelastography
}

\author{
Hasan Yerli', Tuğbahan Yılmaz², Banu Ural², Hüseyin Gülay²
}

\section{ABSTRACT}

'Department of Radiology, Başkent University Zübeyde Hanım Research Center, İzmir, Turkey

2Department of General Surgery, Başkent University Zübeyde Hanım Research Center, İzmir, Turkey

\section{Address for Correspondence}

Dr. Hasan Yerli

Department of Radiology, Başkent University Zübeyde Hanım Research Center, İzmir, Turkey

Phone.: +90232 2411000

e-mail:

hasanyerli@yahoo.com

Received: 26.03 .2013

Accepted: 26.05 .2013

OCopyright 2013 by Turkish Surgical Association

Available online at www.ulusalcerrahidergisi.org
Objective: The aim of this study was to determine whether the use of a scoring method by sonoelastography in solid breast masses is helpful in differentiating benign and malignant lesions.

Material and Methods: One hundred and eighty solid breast masses in 155 patients (147 benign, 33 malignant) were prospectively evaluated in a two-year period. For each lesion, B-mode sonography and sonoelastography images were obtained. Elasticity scores of the lesions were determined with a 5-point scoring method by sonoelastography. The findings were compared with histopathology. The diagnostic performances of the sonoelastographic scoring and B-mode sonography methods were determined.

Results: The mean scores on sonoelastography were $2.61 \pm 0.62$ for benign lesions and $3.73 \pm 0.69$ for malignant lesions. When a cutoff point between scores 3 and 4 was used, accuracy, sensitivity, specificity, positive and negative predictive values for B-mode sonography were found as $81 \%, 89 \%, 79 \%, 46 \%$ and $97 \%$, respectively; these were $87 \%$, $73 \%, 91 \%, 69 \%$ and $92 \%$ for the sonoelastographic scoring method.

Conclusion: After B-mode sonography analysis, the evaluation with the 5-point scoring method by sonoelastography might be a complementary method that increases specificity when differentiating between benign and malignant solid breast masses.

Key Words: Sonoelastography, breast, ultrasonography, neoplasms

\section{INTRODUCTION}

Elasticity is one of the important properties of vital tissues. A certain amount of power should be applied to create elastic deformation. Elasticity is defined as the lengthening change due to tension caused by a certain load on a tissue $(1,2)$. Elasticity property of some masses can be evaluated by physical examination. However, elasticity cannot be examined only by palpation in small or deep located lesions. Besides, manual palpation is a subjective method. A new ultrasonography modality, sonoelastography, evaluates the consistency of tissues. Malignant tissues carry wide desmoplastic reactions therefore they are usually harder than benign tissues and on sonoelastography they are seen as less elastic (1-3). B-mode sonography characterization of breast masses has significantly evolved in the last three decades. The sensitivity of B-mode sonography is high whereas the specifity is relatively low for breast masses. Therefore most biopsies reveal benign lesions on histological evaluation. In recent studies, the sensitivity and specifity of sonoelastography is compared with B-mode sonography, and the diagnostic performance of this method is debated.

In this study, we used sonoelastography method after B-mode sonographic evaluation of solid breast lesions and evaluated the effect of this method on differentiating benign and malignant lesions by elasticity property scores.

\section{MATERIAL AND METHODS}

\section{Patient Selection}

This study was conducted as part of a prospective study that was approved by Başkent University Medical Faculty Medicine and health Sciences Resarch Board (project no, KA 10/50; project approval date, 11.05.2010). Informed consent was obtained from all patients. One hundred eighty patients (age 28-89; mean age, 54) with solid breast lesions, in whom excisional biopsy or surgery was applied, were evaluated during two years. The lesions were evaluated by B-mode sonography and sonoelastography. All evaluations were done prior to biopsy or surgical intervention. Lesions were scored from 1 to 5 by sonoelastography (Table 1). The findings were compared with histopathology results. 
Yerli et al.

Sonoelastography in solid breast masses

\section{B-mode sonography and sonoelastography}

The evaluations were done by EUB-7000 ultrasonography system (Hitachi, Tokyo, Japan) that enables sonoelastographic assessment by "autocorrelation method" together with a linear transducer that enables scanning in the range of 5-10 $\mathrm{MHz}$. The same radiologist, who is experienced in breast imaging, did the B-mode sonography and sonoelastography of the lesions simultaneously. Static and motion images of all cases were recorded to the hard disk of the ultrasonography device.

Transverse and longitudinal plane views were obtained during B-mode ultrasonography. Lesion shape, orientation, border, echogenicity, posterior acoustic shadowing and calcification properties were evaluated by B-mode sonography. The B-mode sonography images were classified according to American College of Radiology's Breast Imaging Reporting and Data System-BIRADS (4). According to this classification category 2 lesions were accepted as benign; category 3 lesions probably benign; category 4 lesions low suspicion for malignancy and category 5 lesions highly suspicious for malignancy. Cases in which no lesions were found were categorized as class 1.

Color-coded maps obtained by sonoelastography method and placed over B-mode sonography views, were evaluated at the same imaging plane with B-mode sonography. In these maps, flexible regions were colored in red and firm lesions in blue. The pressure monitor on the ultrasonography device screen showed levels of 3 or 4 when the transducer was gently pressed over the skin to obtain the required compression to get sonoelastographic images. During the procedure, the vertical amplitude of the transducer was 1-2 $\mathrm{mm}$ and the mean velocity of transducer movement was one or two per second. Lesions were classified according to sonoelastography by 5 score method (5). Diffuse elastic lesions were classified as score 2; predominantly elastic lesions as score 3; predominantly firm lesions as score 4; lesions lacking significant elasticity as score 5 (Table 1, Figure 1-4). Cystic lesions were accepted as category 1 . These lesions showed three-color layers on sonoelastographic evaluation. The scoring of sonoelastographic views were done by two independent reviewers, blinded to the histopathology results, after evaluation of all images separately and subsequent to reaching an agreement. Histopathologic evaluation following excision of the lesion was accepted as standard reference. Elasticity scores were compared with histopathology.

\section{Statistical analysis}

The differences between scores were evaluated by Student's $t$ test. $P<0.05$ was accepted as statistically significant. Accuracy, sensitivity, specificity, positive and negative predictive values were calculated for sonoelastographic scoring and B-mode US sonography. The cut-off value was accepted as score 3 and score 4 in assessing performance of B-mode sonography and sonoelastography methods. Statistical Packages for the Social Sciences (SPSS)11.5 program was used for statistical analysis
Table 1. Sonoelastographic scores for breast lumps

\begin{tabular}{|c|c|}
\hline Score & Sonoelastographic view \\
\hline 1 & Three color layering (blue-green-red) \\
\hline 2 & $\begin{array}{l}\text { Diffuse elastic (near complete green except some } \\
\text { blue dots) }\end{array}$ \\
\hline 3 & $\begin{array}{l}\text { Mostly elastic (mixture of green and blue but } \\
\text { mostly green) }\end{array}$ \\
\hline 4 & $\begin{array}{l}\text { Mostly non-elastic (mixture of green and blue but } \\
\text { mostly blue) }\end{array}$ \\
\hline 5 & Firm (near complete blue) \\
\hline
\end{tabular}

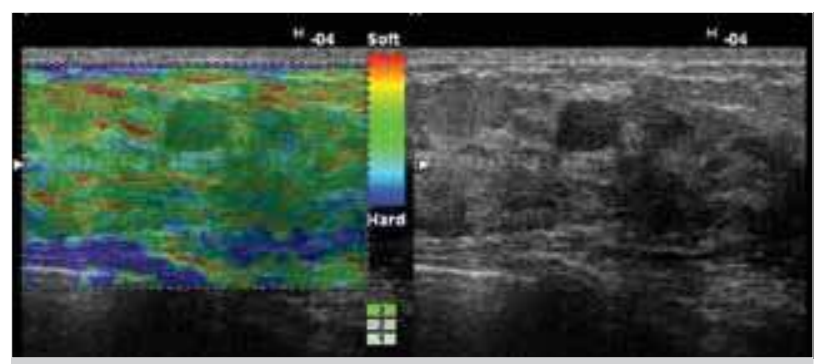

Figure 1. Fifty years-old female with a breast lesion (pathologic diagnosis: Fibroadenoma). Sonoelastograhic score was accepted as 2 due to diffuse elasticity (homogenous diffuse green) (Left side). BIRADS score with B-mode ultrasonography was accepted as category 3 (probably benign) due to hypoechoic lesion with regular borders (right side)

\section{RESULTS}

\section{Lesions}

Table 2 depicts descriptive characteristics of breast lesions. Histopathologic evaluation revealed 147 benign pathologies (81.7\%), and 33 malignant pathologies (18.3\%) in180 lesions. Benign lesion group included 84 fibroadenoma, 34 fibrocystic disease, 7 papilloma, 6 fibroadenolipoma, 4 intraductal epithelial hiperplasia, 5 lipoma, 5 stromal fibrosis and 2 chronic mastitis cases. Malignant lesion group included 26 invasive ductal carcinoma, 4 lobular invasive carcinoma and 3 ductal carcinoma in situ cases. The long axis of 180 lesions werein the range of 5-51 $\mathrm{mm}$ (mean, $14.43 \mathrm{~mm}$ ) and short axis 4-41 mm (mean, $9.36 \mathrm{~mm}$ ).

\section{B-mode sonography and sonoelastography findings}

The mean scores obtained by sonoelastography according to five score method and the mean scores obtained by B-mode sonography according to BI-RADS method are shown in Table 2 . In both methods, calculated mean scores were higher for malignant lesions than benign lesions (Table $2, p<0.05$, Figure 1-4). Table 3 shows histopathologic results and malignancy rates for each score level. A score of 3 was found to be more common in benign lesions both in sonoelastography and in B-mode sonography methods. When a cut-off value of 3 to 4 was used with B-mode scoring method, 38 false positive and 4 false negative results were detected. When scores 1-3 were accepted as benign and scores of 4-5 as malignant sonoelastographic scoring method revealed 15 false positive and 12 false-negative results. In Table 4, B-mode sonography and sonoelastography methods were compared in terms of diagnostic performance. 


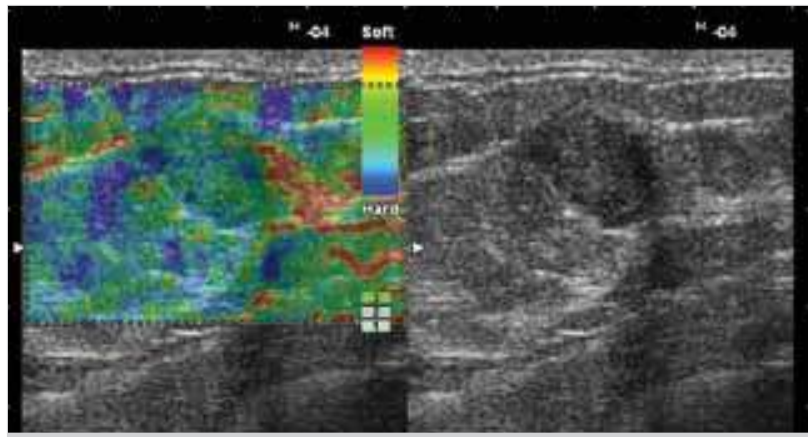

Figure 2. Fourty-six years-old female with a breast lesion (pathologic diagnosis: Fibroadenoma). Sonoelastograhic score was accepted as 3 due to mosaic appearance with abundant elasticity (mostly green) (Left side). BIRADS score with B-mode ultrasonography was accepted as category 4 (low suspicious for malignancy) due to hypoechoic lesion with lobulated borders (right side)

Table 2. Patient age, lesion volume, BI-RADS scores, sonoelastographic scores

\begin{tabular}{|lcc|}
\hline Property & $\begin{array}{c}\text { Benign } \\
(\mathrm{n}=147 ; 81.7 \%)\end{array}$ & $\begin{array}{c}\text { Malignant } \\
(\mathrm{n}=33 ; 18.3 \%)\end{array}$ \\
\hline Age & $49.35 \pm 11.97$ & $59.16 \pm 12.83$ \\
\hline Lesion volume-short axis $(\mathrm{mm})$ & $8.79 \pm 5.24$ & $16.6 \pm 6.89$ \\
\hline Lesion volume- long axis (mm) & $13.68 \pm 7.39$ & $18.48 \pm 8.62$ \\
\hline Method & & \\
B-Mode Sonography & $3.29 \pm 0.61$ & $4.29 \pm 0.66$ \\
(BI-RADS score) & $($ Median: 3$)$ & (Median: 4$)$ \\
\hline Sonoelastographic score & $2.61 \pm 0.62$ & $3.73 \pm 0.69$ \\
& (Median: 3$)$ & (Median: 4) \\
\hline
\end{tabular}

BI-RADS: "Breast imaging reporting and data system"

\section{DISCUSSION}

B-mode sonography is a technique reflecting intensity properties of the tissues examined as brightness on the screen by using acoustic energy interactions in the body (6). The images are in the form of shades of gray, in real time. This method is a commonly used imaging technique to determine both the location and the internal structure of breast masses. Malignant masses can be detected with high sensitivity by B-mode sonography. However, the major problem of this method is the high rate of false positivity. In order to reduce this problem in recent years, research is being done with a new sonography method, sonoelastography.

The firmness of tissues can be displayed with different color codes in real time by sonoelastography and this property can be qualitatively scored. In addition, elasticity maps are also obtained, which enables calculation of stretch stress indexes by comparing the degree of stretching of the normal tissue and that of lesion area and the firmness of the lesion can be expressed quantitatively (7-9). The "Tsukuba elasticity score" proposed by Itoh et al, is widely accepted in the sonoelastographic evaluation of breast masses (10). Tsukuba method classifies the diffuse elastic lesion as score 1; mostly elastic lesions as score 2; peripherally elastic centrally firm lesions as score 3;

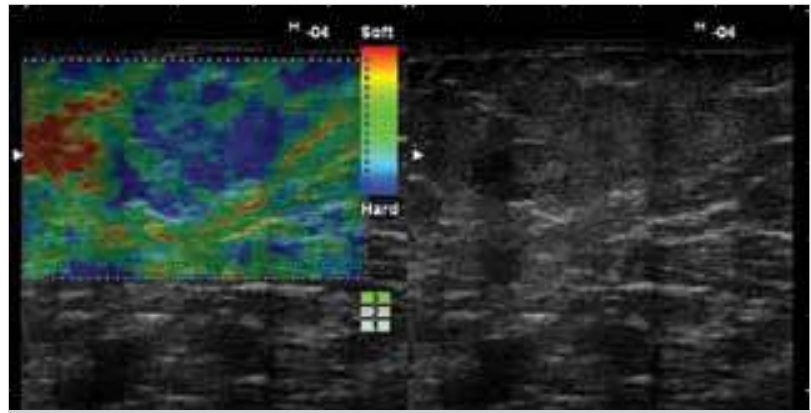

Figure 3. Sixty years-old female with a breast lesion (pathologic diagnosis: invasive ductal carcinoma). Sonoelastograhic score was accepted as 4 due to mosaic appearance with abundant firmness (mostly blue) (Left side). BIRADS score with B-mode ultrasonography was accepted as category 4 (low suspicious for malignancy) due to isoechoic lesion with lobulated borders (right side)

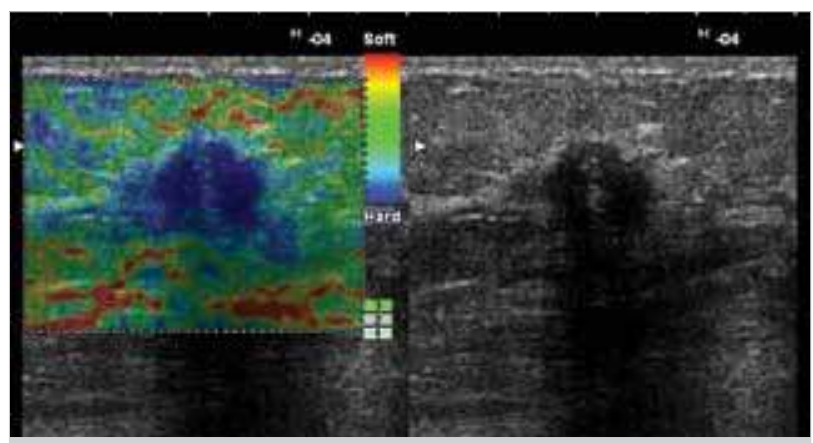

Figure 4. Fifty-five years-old female with a breast lesion (pathologic diagnosis: invasive ductal carcinoma). Sonoelastograhic score was accepted as 5 due to diffuse firmness(almost completely blue) (Left side). BIRADS score with B-mode ultrasonography was accepted as category 5 (highly suspicious for malignancy) due to ill-defined hypoechoic lesion with microcalcifications (right side)

mostly firm lesions as score 4; devoid of significant elasticity and firm even at the periphery of the lesion as score 5. An Italian study group then modified this scoring method (5). In light of our clinical studies with sonoelastography, the modified scoring method was found to be more feasible in the practice of radiology (Table 1). In addition, this scoring method is more compatible with BIRADS. For these reasons, we have used the Italian group's scoring in the evaluation of breast masses by sonoelastography.

Initial studies evaluating sonoelastography in breast masses, revealed low specificity values ranging from $21 \%$ to $56 \%$ (7, $11,12)$. In these studies, neither scoring methods nor quantitative evaluations were performed. Evaluation of lesions was mainly conducted according to area and volume differences between B-mode sonography and sonoelastography. We see that performance values for evaluation of sonoelastography in breast masses have increased by the development of scoring methods in ultrasonography equipments containing "autocorrelation method". Studies using these methods show specificity values of $70 \%$ to $99 \%$, and sensitivity values of $35 \%$ to $97 \%$ (13). In our study, specificity and sensitivity of the sonoelastographic method were found to be $91 \%$ and $73 \%$, re- 


\begin{tabular}{|c|c|c|c|c|}
\hline Method & $\begin{array}{l}\text { Score } \\
\text { Level }\end{array}$ & $\begin{array}{c}\text { Benign } \\
(\mathrm{n}=147 ; 81.7 \%)\end{array}$ & $\begin{array}{c}\text { Malignant } \\
(n=33 ; 18.3 \%)\end{array}$ & $\begin{array}{c}\text { Malignancy } \\
\text { rate (\%) }\end{array}$ \\
\hline \multirow[t]{4}{*}{ B-mode Sonography BI-RADS* Score } & 2 & 10 & 0 & $0 / 10(0)$ \\
\hline & 3 & 99 & 4 & 4/103 (4) \\
\hline & 4 & 34 & 15 & $15 / 49(31)$ \\
\hline & 5 & 4 & 14 & $14 / 18(78)$ \\
\hline \multirow[t]{4}{*}{ Sonoelastographic score } & 2 & 32 & 1 & $1 / 33(3)$ \\
\hline & 3 & 100 & 11 & $11 / 111(9)$ \\
\hline & 4 & 12 & 11 & $11 / 23(48)$ \\
\hline & 5 & 3 & 10 & $10 / 13(77)$ \\
\hline
\end{tabular}

*BI-RADS: "Breast imaging reporting and data system"

Table 4. Comparison of sonoelastography vs. B-mode sonography in distinguishing benign and malignant breast lesions

Diagnostic performance B-mode sonography Sonoelastography

\begin{tabular}{|lll|}
\hline Accuracy (\%) & 81 & 87 \\
\hline Specifity (\%) & 79 & 91 \\
\hline Sensitivity (\%) & 89 & 73 \\
\hline Negative predictive value (\%) & 97 & 92 \\
\hline Positive predictive value (\%) & 46 & 69 \\
\hline
\end{tabular}

spectively. The results of our study were consistent with a most of the studies with scoring methods. Altering the cut-off value is one of the factors that effects specificity and sensitivity of a method. In studies that accept scores of 2 and 3 as the cut-off value, increases sensitivity but decreases specificity. In most of the studies in the literature, the cut-off value is accepted as 3 to 4 .In our study, the specificity of B-mode sonography was found as $79 \%$ and the sensitivity as $89 \%$. The results of our study and most of the literature data, suggest that the sonoelastographic evaluation by 5 score method following B-mode sonography examination can be used as a complementary diagnostic method in order to increase specificity.

In one of the recent studies using quantitative sonoelastography method, it is emphasized that $46 \%$ of unnecessary surgical interventions can be avoided in BI-RADS category 4 lesions (9). Itoh et al. (10) detected no malignancies in 135 breast masses with a score of 1 (according to Tsukuba scoring method). Yi et al. (14) stated that if masses that are category 4a by B-mode sonography and an elasticity score of 1 (according to Tsukuba scoring method) are followed-up instead of performing a biopsy, 38.2\% of biopsies could be avoided. In that study, out of 489 BI-RADS category 4 and elasticity score 1 lesions, only $4(0.8 \%)$ were diagnosed with malignancy, all of which were ductal carcinoma in situ.

As a result, an alternative approach with follow-up instead of biopsy can be recommended to lesions that are category 4a with B-mode sonography and have an elasticity score of 1 factors. With this approach that will significantly reduce unnecessary biopsies, there is a rare risk of overlooking some cancers. Sadighi et al. (13) have done a meta-analysis including 5511 breast masses and have discussed this issue. In their study, they recommended biopsy for the low-risk patient group, if lesions were found to carry low-suspicion for malignancy on B-mode sonography and sonoelastography points out to malignancy. For patients in the high-risk groups, they advocated that a biopsy should be performed if the mass is positive on B-mode sonography regardless of sonoelastography findings.

In our study, out of 180 masses we evaluated the long axis of the smallest mass was $5 \mathrm{~mm}$. Itoh et al. (10) reported the smallest lesion diameter as $4 \mathrm{~mm}$ out of 111 lesions. Scaperrot et al. (5) have evaluated 293 masses, compared performance of sonoelastography for masses of 11 to $20 \mathrm{~mm}$ to those smaller than $10 \mathrm{~mm}$ in size, and they did not find a significant difference in the performance of the method.

The main limitation of our study is the lack of inter-observer compatibility study. Another restriction is that sonoelastography evaluation could not be performed independently from B-mode sonography evaluation. This was due to performing sonoelastography evaluation, by placing images on B-mode sonography views and using color-coded maps.

\section{CONCLUSION}

Qualitative analysis by sonoelastography scores in combination with B-mode sonography, of breast masses might be a diagnostic tool that increases specificity. Therefore, this method may be helpful in planning biopsy of lesions and avoiding unnecessary procedures.

Ethics Committee Approval: Ethics committee approval was received for this study from the ethics committee of Başkent University School of Medicine (11.05.2010, KA 10/50).

Informed Consent: Written informed consent was obtained from patients who participated in this study.

Peer-review: Externally peer-reviewed. 
Author Contributions: Concept - H.Y.; Design - H.Y., T.Y., B.U., H.G.; Supervision - H.Y.; Funding - H.Y.; Materials - T.Y., B.U., H.G.; Data Collection and/or Processing - T.Y., B.U., H.G., H.Y.; Analysis and/or Interpretation - H.Y.; Literature Review - H.Y.; Writer - H.Y.; Critical Review - H.Y.

Conflict of Interest: No conflict of interest was declared by the authors.

Financial Disclosure: The authors declared that this study has received no financial support.

\section{REFERENCES}

1. Ophir J, Céspedes I, Ponnekanti H, Yazdi Y, Li X. Elastography: a quantitative method for imaging the elasticity of biological tissues. Ultrason Imaging 1991; 13: 111-134. [CrossRef]

2. Gao L, Parker KJ, Lerner RM, Levinson SF. Imaging of the elastic properties of tissue-a review. Ultrasound Med Biol 1996; 22: 959-977. [CrossRef]

3. Chen EJ, Adler RS, Carson PL, Jenkins WK, O'Brien WD Jr. Ultrasound tissue displacement imaging with application to breast cancer. Ultrasound Med Biol 1995; 21: 1153-1162. [CrossRef]

4. American College of Radiology. Breast imaging reporting and data system (BI-RADS): Ultrasound. Reston, Information website: http:// www.acr.org/s_acr/sec.asp?CID=882\&DID=14550. Accessed September 8, 2004.

5. Scaperrotta G, Ferranti C, Costa C, Mariani L, Marchesini M, Suman L, et al. Role of sonoelastography in non-palpable breast lesions. Eur Radiol 2008; 18: 2381-2389. [CrossRef]

6. Merritt CRB. Physics of ultrasound. In: Rumack CM, Wilson SR, Charboneau JW(eds). Diagnostic Ultrasound. 2nd ed. St Louis, MO: CV Mosby Co; 1997: 3-33.
7. Garra BS, Cespedes El, Ophir J, Spratt SR, Zuurbier RA, Magnant CM, et al. Elastography of breast lesions: initial clinical results. Radiology 1997; 202: 79-86.

8. Yerli H, Yılmaz T, Kaskatı T, Gülay H. Qualitative and semi-quantitative evaluations of solid breast lesions by sonoelastography. J Ultrasound Med 2011; 30: 179-186.

9. Athanasiou A, Tardivon A, Tanter M, Sigal-Zafrani B, Bercoff J, Deffie$\mathrm{ux} T$, et al. Breast lesions: quantitative elastography with supersonic shear imaging--preliminary results. Radiology 2010; 256: 297-303. [CrossRef]

10. Itoh A, Ueno E, Tohno E, Kamma H, Takahashi H, Shiina T, et al. Breast disease: clinical application of US elastography for diagnosis. Radiology 2006; 239: 341-350. [CrossRef]

11. Regner DM, Hesley GK, Hangiandreou NJ, Morton MJ, Nordland MR, Meixner DD, et al. Breast lesions: evaluation with US strain imaging--clinical experience of multiple observers. Radiology 2006; 238: 425-437. [CrossRef]

12. Burnside ES, Hall TJ, Sommer AM, Hesley GK, Sisney GA, Svensson $W E$, et al. Differentiating benign from malignant solid breast masses with US strain imaging. Radiology 2007; 245: 401-410. [CrossRef]

13. Sadigh G, Carlos RC, Neal CH, Dwamena BA. Ultrasonographic differentiation of malignant from benign breast lesions: a meta-analytic comparison of elasticity and BIRADS scoring. Breast Cancer Res Treat 2012; 133: 23-35. [CrossRef]

14. Yi A, Cho N, Chang JM, Koo HR, La Yun B, Moon WK. Sonoelastography for 1,786 non-palpable breast masses: diagnostic value in the decision to biopsy. Eur Radiol 2012; 22: 1033-1040. [CrossRef] 